Rodkjaer $\mathrm{L}^{1 *}$, Seeberg $\mathrm{K}^{2}$, Laursen $\mathrm{T}^{1}$, Dalum $\mathbf{A}^{1}$, Tolstrup $\mathbf{M}^{1}$, Drouin $\mathbf{M}^{1}$, Sommer $\mathrm{M}^{1}$, Dahl $\mathrm{K}^{1}$, Dyrehave $\mathrm{C}^{1}$ and Ostergaard $\mathrm{L}^{1}$

${ }^{1}$ Department of Infectious Diseases, Aarhus

University Hospital, Brendstrupgaardsvej 100, 8200

Aarhus N, Denmark

${ }^{2}$ Cubion A/S, Fredensgade 36, 8000 Aarhus C, Denmark

Dates: Received: June 28, 2014; Accepted: August 16, 2014; Published: August 18, 2014

*Corresponding author: Lotte Rodkjaer, $\mathrm{MPH}, \mathrm{PhD}$, Associate Professor, Department of Infectious Diseases, Aarhus University Hospital, Brendstrupgaardvej 100,8200 Aarhus N, Denmark, Email: lottrodk@rm.dk

www.peertechz.com

Keywords: HIVIAIDS; Depression; Selfefficacy; Coping; Complex intervention

\section{Research Article \\ The Impact of a Holistic Intervention on Self-Efficacy and Risk of Depression in HIV-Infected Individuals in Denmark}

\begin{abstract}
Introduction: Human immunodeficiency virus (HIV) infection is a stressful disease, and depression is frequently experienced by HIV-infected individuals. The aim of this pilot study was to investigate whether a holistic intervention could improve coping self-efficacy strategies and have a positive impact on the mental health of HIV-infected individuals 12 months posterior to the intervention.
\end{abstract}

Method: From January 2010-January 2011, a total of 30 HIV-infected individuals at the Department of Infectious Diseases at Aarhus University Hospital, Denmark were included in the study. The intervention was a group intervention and was facilitated by an educated coach. It was organized as a three day residential course as well as 6 single day follows up events spread out over 6 months.

The main outcome measures were coping self-efficacy (self-efficacy as defined as the belief in one's ability to perform a specific behavior) and depression. The intervention was evaluated 12 months after the end of the intervention.

Results: Twenty individuals completed the intervention. Coping self-efficacy and psychological health improved overall, and there was a significant decrease in depression $(p=0.0017)$. The qualitative interview results supported the questionnaire results, displaying changes in bodily sensation, in awareness, in understanding and insight, in behaviour and in actions as well as the development of new competences. The individuals felt more in balance (e.g. emotional stability), and this feeling of being more competent in terms of managing the disease was maintained at the 12-month follow-up.

Conclusion: These results will be useful for developing effective interventions that help individuals manage the acute and chronic stress of living with HIV and increase coping self-efficacy, thereby preventing depression. These results merit further investigation in a randomized controlled trial.

\section{Introduction}

Due to the successful treatment of human immunodeficiency virus (HIV) with highly active antiretroviral therapy (HAART) $[1,2]$. HIV infection is now considered a chronic condition, and the life expectancy of HIV-infected individuals is approaching that of the background population [2]. Sub-optimal adherence to antiretroviral therapy is the most common cause of virologic failure and will, in the long-term, lead to an increased risk of drug resistance and disease progression [3-7]. Furthermore, concerns about the consequences of inadvertent disease disclosure can interfere with self-care efforts [8-10]. Depression is the most common form of psychological distress experienced by those living with HIV, and depression is both under-diagnosed and under-treated within this population group. Up to one third of persons livings with HIV have mood disorders or clinically significant depressive symptoms [11-13]. Depressive symptoms and stress have been linked to HIV disease progression, but the association between HIV and depression is unclear [14-16]. Depression is attributed to multiple factors, including physical factors (e.g. the progression of HIV-related symptoms) and psychological factors (e.g. prior psychiatric history and stress); factors specific to the patient and those related to antiretroviral treatment [17-19]. Several studies that examined depression at the initiation of HAART found that individuals with depression exhibited over five times the risk of clinical progression to AIDS, [13,20] slower viral suppression [21,22] and a decreased survival rate [22]. We previously investigated the prevalence of depression in HIV-infected individuals and identified factors that were associated with the risk of depression in a Danish setting $[23,24]$. Our studies confirmed that depression is both underdiagnosed and under-treated. In addition, our findings showed that living with HIV is as much a psychological and social concern as a medical concern. Disclosure is a continuous challenge and a potential HIV-related stressor [25]. It has independently been shown that positive psychological states aid a less rapid HIV disease progression 
[26-36] and that a positive psychological adjustment to chronic disease leads to an increased participation in self-management and increased self-efficacy [36]. Self-efficacy is here defined as the belief in one's ability to perform a specific behavior [37-39]. Individuals with high self-efficacy are better able to motivate themselves and to persevere when difficulties arise, should be less vulnerable to stress and should be more resilient after aversive stimuli [40]. Coping has been the focus of research in the social sciences for a long time and is understood as a complex multidimensional process that is sensitive to the environment (i.e., to environmental demands and resources) and to personality dispositions that influence the appraisal of stress and coping resources. When people achieve a good 'fit' between stressful events and their coping strategies, they experience fewer psychological symptoms than when there is a lack of fit. Specifically, a person's belief in their efficacy determines which knowledge they acquire and thus on which foundation they base their skills [38]. This also determines the likelihood that knowledge and skills will be translated into adaptive behaviors.

Coping is considered one of the core concepts in health psychology and is strongly associated with the regulation of emotions in response to social and environmental stressors. Coping self-efficacy is based on the idea that people need to have coping self-efficacy in order to effectively engage in adaptive coping behaviors [41]. Several studies have concluded that, overall, stress-management interventions can substantially improve the mental health and quality of life in HIVinfected persons $[26,42,43]$. However, few studies have investigated whether the benefits of such interventions are maintained in the longterm [26].

The aim of this study was to investigate whether a holistic intervention (considers the whole person physically and psychologically, in the quest for optimal health and wellness) could improve the coping self-efficacy strategies of HIV-infected individuals, have a positive impact on mental health and be maintained 12 months after the intervention.

\section{Methods}

\section{Study group}

From January 2010-January 2011, a total of 30 HIV-infected individuals ( 8 women and 22 men) were recruited for the study. The outpatient clinic at the Department of Infectious Diseases at Aarhus University Hospital provides care for $14 \%(\mathrm{~N}=4627)$ of the total HIV-positive population in Denmark.

Inclusion criteria were as follows: aged 18 years or older; the occurrence of two or more missed scheduled quarterly appointments; and the presence of physical problems (e.g. pain, side effects, low adherence), psychological problems (e.g. depression, anxiety, non-disclosure of HIV status, stress, loneliness, divorce) or social problems (e.g. economy, unemployed). We screened the patient group according to the above mentioned inclusion criteria and found $50 \mathrm{HIV}$-infected individuals who were eligible for the study. They were invited to participate in the study and to attend a meeting with more detailed information. 30 individuals asked to be enrolled and they were divided into two groups (15 persons in each group) according to which dates that suited the persons best. The study was approved by the Aarhus Health Human Research Ethics Committee and the Danish Data Protection Agency.

\section{Intervention}

The intervention was a group intervention facilitated by an educated coach. Both groups were offered the same intervention. The framework was a three-day residential course plus six single-day/eight hour follow-up events/monthly. The total length of the intervention was 6 months. Table 1 shows the main framework for and content of the intervention. The focus of the intervention was to improve each person's coping self-efficacy in order for them to gain an improved balance in their lives (a stable mental or psychological state; emotional stability). The intervention was based primarily on a Native American philosophy of life [44] and its understanding of how changes affect human beings and create imbalance. According to this philosophy, change can be understood as a dynamic force that moves people from one point to another. However, it also acknowledges that people have different ways of facing change. The 'Wheel of Change' (Figure 1) illustrates the movement from denial over reaction to acceptance and finally to action and shows how the stages are connected to conscious and unconscious behavior. The Wheel of Change is the core starting point for the intervention. The intervention offers various tools and principles that focus on whether a person chooses 'warrior 'or 'victim' behaviors when facing challenges in his/her daily life (Figure 2). The way in which people deal with challenges determines whether, in a given situation, he or she assumes the stance of warrior or victim. The source of the warrior is love and courage while the source of the victim is fear. Once it is clear that the source of certain reactions is fear, the person becomes more conscious of how he or she reacts and is then able to develop a new ability to act. The focus of the intervention is on how to accept and recognize one's current situation and find one's own tools to act as a warrior [44].

\section{Questionnaire}

Participants filled out a self-reported standardized questionnaire before starting the intervention (baseline) and 12 months after the intervention was completed (follow-up). The following data was recorded: gender, age, educational level, current job, marital status, current HIV treatment and adherence, current financial situation, route of infection, HIV exposure group, sex life, co-morbidities, smoking and drug habits, depression, alternative treatment, coping self-efficacy, disclosure and psychological factors associated with living with HIV, The Short-Form Health Survey (SF-36), The Sense of Coherence (SOC) Scale, The coping self-efficacy scale (CSE), The Beck Depression Inventory II (BDI).

The Short-Form Health Survey (SF-36) [45] is a multi-purpose, short-form health survey with 36 questions that yields an 8 -scale profile of functional health and well-being scores as well as psychometrically-based physical and mental health summary measures and a preference-based health utility index. The Sense of Coherence (SOC) Scale [46], the SOC, is defined as: "The extent to which one has a pervasive, enduring though dynamic, feeling of confidence that one's environment is predictable and that thing will work out as well as can reasonably be expected." It includes three components: 1) Comprehensibility (the extent to which stimuli from one's external and internal environments are structured, explicable 
Table 1: Main frame and content of the intervention.

\begin{tabular}{|c|c|c|}
\hline & Themes & The setting \\
\hline Three day residential course & $\begin{array}{l}\text { The Wheel of change (Figure 1) } \\
\text { The Wheel of Change is the the essential starting point for the } \\
\text { intervention. } \\
\text { When you meet a challenge you go through a process in order to } \\
\text { gain balance again. The movement goes from denial over reaction } \\
\text { to acceptance and finally to action, but it is not necessarily a } \\
\text { straight forward process. The stages are connected to conscious } \\
\text { and unconscious behavior. } \\
\text { The purpose is to be aware of your unconscious behavior which } \\
\text { causes unbalance in order to be able to do something to regain } \\
\text { balance in life. } \\
\text { The task and challenge is to learn to become conscious of the } \\
\text { unconscious } \\
\text { Warrior/Victim (Figure 2) } \\
\text { The intervention focuses on various tools and principles that } \\
\text { primarily intend to shed ligght on whether a person chooses } \\
\text { 'warrior' or 'victim' behavior when handling challenges in daily life. } \\
\text { We are not either a warrior or a victim - we contain both } \\
\text { The source of the warrior is love and courage, while the source of } \\
\text { the victim is fear. } \\
\text { The task and challenge is how one can accept and recognize the } \\
\text { current situation and find the tools to act as a warrior } \\
\text { "The five questions" (The warrior's weapon) } \\
\text { Understand that the fear is not an enemy. The fear is teaching us } \\
\text { a lesson. It is trying to teach us what I have to do. You don't get rid } \\
\text { of it - you integrate it. } \\
\text { When you face fear: } \\
\text { 1) Breathe } \\
\text { 2) Connect, feel, accept } \\
\text { 3) Ask the five questions and identify the fear } \\
\text { Who; am I afraid of? } \\
\text { What, am I afraid of? } \\
\text { Where, do I feel the fear? } \\
\text { When; does the fear occur? } \\
\text { How; does the fear affect me? } \\
\text { Y) cannot change the other person - you can change yourself }\end{array}$ & $\begin{array}{l}\text { To create the setting, the coach first of all ensured a safe } \\
\text { environment of trust and respect, which is crucial and the main } \\
\text { condition to be able to open up and work with private challenges. } \\
\text { The participants were seated in a circle. } \\
\text { The circle is the pattern of harmony, according to the native } \\
\text { Indians. } \\
\text { Initial a feather was send from one person to the next in the circle } \\
\text { and the person with the feather was speaking and the rest were } \\
\text { listening. This was how all gatherings started. } \\
\text { On the first day the coach was introducing the participants to do } \\
\text { small grounding exercises. The coach mainly used own cases as } \\
\text { examples. Slowly the participants were getting more involved and } \\
\text { was bringing in own experiences and examples. } \\
\text { On the second day the coach was asking for the participant } \\
\text { involvement and slowly during the day they brought in more cases } \\
\text { and examples. No one felt forced to bring it is and only at the end } \\
\text { of the day they were asked to make an exercise, where they were } \\
\text { paired two and two and had to tell about own experience of tear to } \\
\text { each other. } \\
\text { The exercise was marking a shift in the intimacy of the group. The } \\
\text { coach to the participants, that the name of the course really was 'I } \\
\text { How to grow up and be an adult' } \\
\text { There had been build up an atmosphere of confidence in the group } \\
\text { and the participants got more and more involved in exercises and } \\
\text { the cases. } \\
\text { Each participants refer to the three day residential course, and } \\
\text { where they experienced their turning point. }\end{array}$ \\
\hline Six single days follow up & $\begin{array}{l}\text { The six follow up days all put layers to the central themes the } \\
\text { participants were introduced to during the residential course. They } \\
\text { were introduced to new grounding and mediation exercises, which } \\
\text { gave participants a variation of exercises to choose from. } \\
\text { They gradual recognize that they have the resources themselves - } \\
\text { they just have to rediscover them. } \\
\text { The participants were constantly being reminded of the value of } \\
\text { practicing and facing challenges and learn from it. } \\
\text { What you train- is what you do }\end{array}$ & $\begin{array}{l}\text { The follow up days were all based on group sessions and the } \\
\text { circle was the setting. The participants did bring in their own } \\
\text { cases and examples during the session. The group/circle was an } \\
\text { important and safe place of exercising. Participants emphasized } \\
\text { that they learned as much from listening to a co-participants story } \\
\text { as when they themselves did bring in a case or an example during } \\
\text { session. }\end{array}$ \\
\hline Practice in between & $\begin{array}{l}\text { Exercises of own choice: Breath work, Grounding, Getting } \\
\text { conscious of the unconscious, Face fear etc. }\end{array}$ & $\begin{array}{l}\text { The participants effort of exercising differed as did the speed and } \\
\text { depth of change. }\end{array}$ \\
\hline
\end{tabular}

and predictable), 2) Manageability (the extent to which resources are available to a person to meet the demands posed by these stimuli) and 3) Meaningfulness (the extent to which these demands are challenges worthy of investment and engagement). SOC is strongly related to perceived health, especially mental health, and having a strong SOC may protect against depression, so SOC can be useful for identifying people who can be helped by psychological interventions. The SOC scale has a seven-point Likert scale format with two anchoring responses, 'never' and 'very often'. The points that were measured were perceived comprehensibility, manageability and meaningfulness. The score ranges from 13-91, a high score indicating a strong SOC. The coping self-efficacy scale (CSE) [47] provides an alternate approach to the measurement of adaptive or positive coping for intervention studies. The CSE scale assesses a person's confidence with respect to carrying out various key coping behaviors (adaptive), such as seeking social support and finding solutions to problems, so that the CSE score reflects the individual's confidence regarding his or her ability to effectively cope with or manage problems. The CSE was assessed with a 26-item measure of perceived self-efficacy for coping with challenges and threats. Subjects were asked to use 


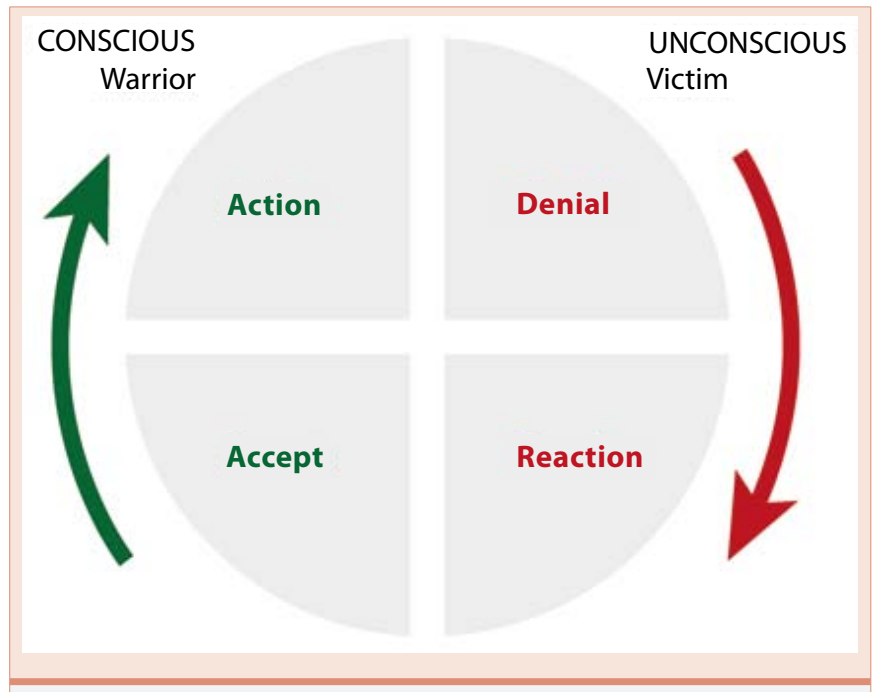

Figure 1: Wheel of Change.

\begin{tabular}{|l|l|}
\hline \multicolumn{1}{|c|}{ Warrior } & \multicolumn{1}{c|}{ Victim } \\
\hline Takes responsibility & Blames others \\
Proactive & Reactive \\
Makes life happen "Change" & Life happens \\
Open, flexible & Closed, rigid \\
Sees choices and options & Is stuck, has exuces \\
\hline
\end{tabular}

Figure 2: Characteristic warrior and victim behaviours.

an 11-point scale to rate the extent to which they believe they could perform behaviors that were important to adaptive coping, such as 'differentiate between what can be changed and what cannot be changed', 'break an upsetting problem down into smaller parts', 'look for something good in a negative situation' and 'receive emotional support from friends and family'. Anchor points on the scale were 0 ('unable'), 5 ('moderately able') and 10 ('certainly able'). The Beck Depression Inventory II (BDI) [48] was used to assess the prevalence and severity of depressive symptoms. The BDI has shown high validity and reliability in measuring depressive symptoms and has acceptable test-retest reliability in a nonclinical population. The respondents rated 21 items on a scale from 0 to 3 according to how they had felt during the preceding 2 weeks. The BDI focuses on both the cognitiveaffective symptoms of depression, e.g. pessimism and diminished self-esteem as well as on the somatic symptoms of depression, e.g. weight loss. A BDI score $\geq 14$ is widely accepted as an indication of depression. In this study, the BDI score categories were interpreted as follows: $0-13$, no/minimal depression; 14-19, mild depression; 20-28, moderate depression; 29-63, major depression.

\section{Qualitative interviews}

Semi-structured in-depth interviews were conducted with each participant at the end of the intervention by a trained anthropologist. The interviews inquired about the following topics: the motivations for participating in the intervention, what had been the best qualities of the intervention, considerations about joining a group intervention, cognition gained from participation and changes in one's own behavior as perceived by oneself and as perceived by one's friends and family. The qualitative data was analyzed using a thematic framework analysis [49].

\section{Statistical analysis}

The statistical analyses were performed using STATA 10 [50]. All data from the questionnaires was double-entered. All statistical analyses were non-parametric as the sample size was too small to assume that the sample data was normally distributed. All parameters were analysed as paired data (baseline versus follow-up), and we used the Wilcoxon matched-pairs signed-rank test to show changes in depression. A p-value $<0.05$ was considered statistically significant. When comparing two parameters, linear regression was used to test for correlations.

\section{Results}

In January of 2010, 30 HIV-infected individuals, 8 women and 22 men, were enrolled in the study.

These individuals have lived with their HIV-status for anywhere between 2-26 years. Twenty participants completed the intervention but only 19 turned in questionnaires filled out at baseline and at the 12-month follow-up. Seven participants stopped after the three-day residential course. The reasons for stopping were as follows: two had severe psychological problems; three concluded that the intervention was "not right for me"; and two began new jobs. Three participants almost completed the intervention but stopped before the last followup day due to practical reasons.

The questionnaire results, qualitative interview results as well as their associations with the outcome of the intervention are reported below.

\section{Questionnaires}

The participants were mostly male (74\%), and $58 \%$ were between 41 and 50 years old (Table 2). Overall, 58\% had co-morbidities (hypertension, diabetes, hepatitis $\mathrm{B} / \mathrm{C}$, asthma or mental illness). The prevalence of symptoms of depression is shown in table 3 .

At baseline, 5 individuals had a BDI $>20$, indicating moderate to severe depression. At follow-up, this number decreased by $80 \%$, and only 1 individual was depressed. The median BDI score was 11 at baseline and 4 at follow-up. A Wilcox on matched-pairs signedrank test showed a significant decrease in depression from baseline to follow-up ( $\mathrm{p}=0.0017$; Figure 3). A total of $53 \%$ of the individuals had diagnosable depression at some point in their lives. The median BDI scores both at baseline and at follow-up fell into the lower range (0-13), indicating minimal depression. Looking at the interquartile ranges, the upper quartile was 19 at baseline and 9 at follow-up. Five individuals had moderate to severe depression at baseline, while only one had moderate to severe depression at the follow-up.

There was an overall improvement from baseline to follow-up as there was a decrease in the influence of emotional factors on dayto-day life with HIV. In terms of coping self-efficacy, there was an overall increase in self-efficacy from baseline to follow-up, indicating increased confidence in performing coping behaviors when faced 
with life challenges (Figure 4). The participants reported a better self-rated health at follow-up (SF-36) and overall results indicated improved psychological health and unchanged physical health (SF36) at follow-up as compared to that at baseline. The participants also reported an increased SOC.

\section{Qualitative interviews}

In-depth interviews were conducted with the 20 participants that had attended all sessions and the 3 participants who stopped before the last session ( $77 \%$ of the participants). Overall, participants

Tabel 2: Characteristics of the 19 HIV-infected individuals in the interventional study..

\begin{tabular}{|c|c|c|}
\hline & $\mathbf{N}$ & \\
\hline & 19 & $\%$ \\
\hline \multicolumn{3}{|l|}{ Gender } \\
\hline Men & 14 & 74 \\
\hline Women & 5 & 26 \\
\hline \multicolumn{3}{|l|}{ Age } \\
\hline $31-40$ & 3 & 16 \\
\hline $41-50$ & 11 & 58 \\
\hline $51-60$ & 4 & 21 \\
\hline $60+$ & 1 & 5 \\
\hline \multicolumn{3}{|l|}{ Etnicitet } \\
\hline Denmark & 19 & \\
\hline \multicolumn{3}{|l|}{ Education } \\
\hline A few years of higher education (1/2 year-2years) & 3 & 16 \\
\hline More years of higher education (3-4 years) & 14 & 74 \\
\hline Completed or almost completed higher education (more than 4 years) & 1 & 5 \\
\hline No education after secondary school & 1 & 5 \\
\hline \multicolumn{3}{|l|}{ Work } \\
\hline Employed & 11 & 58 \\
\hline Rehabilitation, social security, sickness or disability support pension & 3 & 16 \\
\hline Incapacity benefit & 3 & 16 \\
\hline Other & 3 & 11 \\
\hline \multicolumn{3}{|l|}{ Married/has a partner } \\
\hline Yes & 11 & 58 \\
\hline \multicolumn{3}{|l|}{ Children } \\
\hline Yes & 11 & 58 \\
\hline \multicolumn{3}{|l|}{ HIV exposure groups } \\
\hline Homosexual & 8 & 42 \\
\hline Heterosexual & 10 & 53 \\
\hline Bisexual & 1 & 5 \\
\hline \multicolumn{3}{|l|}{ Co-morbidity } \\
\hline Yes & 11 & 58 \\
\hline Hypertension & 2 & \\
\hline Hepatitis B,C & 3 & \\
\hline Asthma & 3 & \\
\hline Mental diseases & 4 & \\
\hline Decreased lung function & 1 & \\
\hline
\end{tabular}

*Twenty participants completed the intervention but only 19 turned in the questionnaires at baseline and follow-up.
Table 3: The prevalence of depressive symptoms and diagnosed depression among the 19 HIV-infected individuals in the interventional study.

\begin{tabular}{|l|l|c|c|c|c|}
\hline \multicolumn{2}{|l|}{ Becks Depression Inventory II } & Baseline & \multicolumn{3}{|c|}{ Follow-up } \\
\hline Score & & N & N & \\
\hline Minimal & $0-13$ & 11 & 58 & 17 & 90 \\
\hline Mild & $14-19$ & 3 & 16 & 1 & 5 \\
\hline Moderate & $20-28$ & 3 & 16 & 1 & 5 \\
\hline Major & $29-63$ & 2 & 10 & 0 & 0 \\
\hline Previous diagnosed with depression & 10 & 53 & & \\
\hline Pre HIV-diagnosis & 3 & 16 & & \\
\hline \multicolumn{2}{|l|}{ Post HIV-diagnosis } & 6 & 32 & & \\
\hline
\end{tabular}

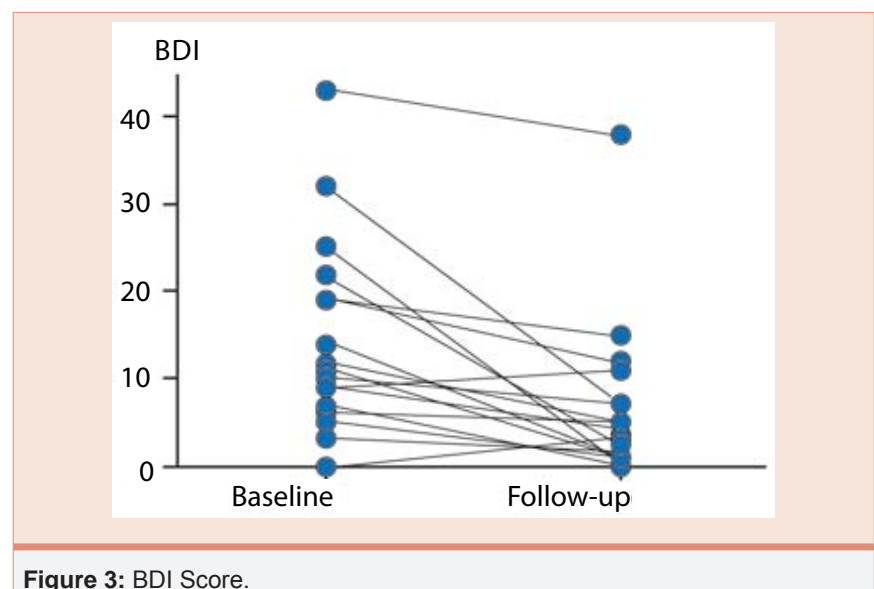

Figure 3: BDI Score.

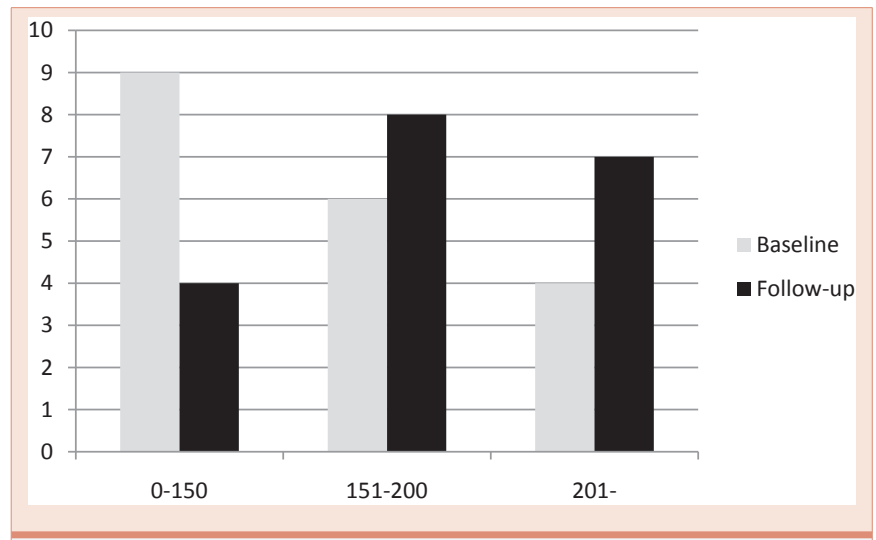

Figure 4: Coping Self-efficacy Scale scores for the 19 HIV-positive subjects in the interventional study at baseline and at a 12-month follow-up. This 26-item scale measures one's confidence in performing coping behaviours when faced with life challenges.

indicated changes in body sensation; in awareness, understanding and insight; in behaviour; in actions; and in the development of new competences as one's own "HIV-manager". Many of the participants emphasised that they had become more conscious of how they behave in different situations. This consciousness of how they react to various obstacles and unpredictable situations presented 
an opportunity to change their behaviour and gain control of their daily life. This new awareness was supported by various tools and techniques of meditation and breathing exercises. The techniques of gaining control were implemented in daily life situations and did not call for withdrawal. Each participant found what suited him or her best and this was one of the strengths that participants emphasised as unique for this intervention; that there wasn't one right solution to follow; instead you had to find one that worked for you. As they reclaimed control over their lives, some also gained the courage to tell relatives about their HIV status, others realised they had to change profession and some stopped using anti-depression drugs. Of the 20 persons that completed the intervention, all mentioned changes that they themselves had felt, and for half of the group people close to them had likewise noticed a change, that they had become more optimistic and more straight-forward. The intervention made it clear to the participants that many of the obstacles they were facing were not due to their HIV status, and that by accepting HIV as a condition they had to cope with, the disease became just an element of their personal story rather than an overshadowing identity. Although they still experience their HIV as a stigma in society, they have gained strategies to cope with their situation.

\section{Discussion}

Our findings indicated that a holistic intervention improved the psychological health (SF-36) and the coping self-efficacy strategies (CSE) of the HIV-infected individuals in this study. In addition, there was a significant decrease in depression (BDI-II). The participants reported unchanged physical health (SF-36); thus we conclude that the intervention did not do any harm. In addition, the subjects' SOC improved. Notably, this scale can be thought of as a prognostic indicator of the outcome of the individual's rehabilitation process. The result indicates a gain in balance and emotional stability and a stable mental or psychological state in terms of living with HIV. The SOC measures the internal capacity to manage changes in life situations without neglecting one's health. The consistency between the SF-36 and the SOC responses supports this conclusion.

The intervention had a positive impact on the severity of depression as measured by the BDI-II score. A review by de Ridder et al. [36] concluded that to promote psychological adjustment, patients with chronic diseases should remain as active as is reasonably possible, acknowledge and express their emotions in a way that allows for them to take control of their lives, engage in self-management and try to focus on potential positive outcomes of their illness. Patients who can use these strategies have the best chance of successfully adjusting to the challenges posed by a chronic illness. The decrease in depression might be due to increased coping self-efficacy as, in general, a person with a strong SOC is more likely to feel less stress and tension and to believe that he or she can meet the demands of daily life; thus, a strong SOC is a protective factor against depression [51]. As a strong SOC may protect against depression, SOC may be useful for identifying individuals who are likely to benefit from psychological interventions $[52,53]$. The participants reported a better self-rated health at the follow-up. Self-rated bad health has been linked to being a strong predictor for mortality in HIV-infected individuals [54].
A meta-analysis conducted by Chida et al. [55] showed that personality types or coping styles and psychological distress were more strongly associated with greater HIV disease progression than stress stimuli per se. Other studies found that for HIV-infected individuals coping with stressors, avoidant coping and disengagement coping styles were related to increased anxiety and depression [56,57], while decreases in avoidant coping following interventions were related to decreased depression and grief [58,59]. We conducted a study investigating the relationship between coping self-efficacy levels, as determined by the CSE, HIV status disclosure and depression in a Danish cohort [60]. The study revealed that those with low CSE scores were more likely to report living secretly with HIV and to be depressed. Disclosing HIV may constitute a social stressor, and a lack of coping self-efficacy may increase the likelihood of non-disclosure and depression.

Results from the qualitative interviews supported the questionnaire results and indicated that the participants experienced: 1) Changes in body sensation (e.g. decreased symptoms of depression, increased quality of life, increased self-reported health); 2) Changes in awareness, understanding and insight (including being able to understand HIV in ways that differed from their biomedical understanding); 3) Changes in behavior and actions and the development of new competences in their role as "HIV manager" (e.g. increased coping self-efficacy, increased SOC, decreased HIVrelated stressors, developing their own resources/motivations, more tools to handle life situations, greater knowledge and more tools to help prevent symptoms and promote health).

This study was a pilot study of a complex intervention and is, to our knowledge, the first study to use a Native American Philosophy approach. The definition of a complex intervention is one that is "built up from a number of components which may act both independently and interdependently" and early phase research is needed to define the "active ingredients" of the intervention [61,62]. It is difficult to evaluate a complex intervention due to problems inherent in developing, identifying, documenting and reproducing the intervention. Complex interventions are directed at the person as a whole and require use of both qualitative and quantitative evidence $[61,62]$. We used both qualitative and quantitative methods to measure aspects of the changes that took place during the intervention. Furthermore, the results of the intervention depend on both the contextual and communicative aspects of the intervention, the resources of the individual such as the body's ability to heal itself and the impact of the individual's situation. Therefore measurement of the outcome is not a single endpoint with a linear cause. Rather, the individual is an active agent who will interact with an intervention in ways that produce individualised changes. Changes in immune status may emerge over longer periods, and randomised controlled trials (RCT) with sufficient statistical power should include longterm follow-up assessments to conduct more definitive tests of the effects of the intervention on HIV disease markers [63]. The assumptions that underlie the intervention should be identified as well as its process and context. This is beyond the scope of this study but should be explored further in an RCT as the next step in developing an intervention $[60,61]$. There is insufficient evidence to draw conclusions regarding the long-term outcomes of HIV- 
specific self-management interventions [26]. We believe that these results offer information that can be valuable for developing effective interventions.

The study has some limitations. One limitation is the small number of participants: $20 \mathrm{HIV}$-infected individuals $(67 \%$ of the study group) finished the intervention at the 12-month follow-up. The small size of the study decreases the statistical power of the analysis of the results of the questionnaires and increases the likelihood of bias, but the qualitative data supports the quantitative findings. The lack of a control group is a considerable limitation as the results could be attributed to natural fluctuations, improvements of individuals over time, changes in treatment, the characteristics of the participants (e.g. age, gender, amount of time living with HIV-status, ethnicity) and other uncontrolled variables.

In conclusion, the findings from this study are useful for developing effective interventions that help HIV-infected individuals to increase their coping self-efficacy and thereby prevent depression over the long term. These findings add to our understanding of a more holistic approach to patient care and might lead to an increased coping self-efficacy for patients as well as an increased involvement and responsibility for patients' own health. This merits further investigation in an RCT.

\section{Acknowledgments}

The authors are grateful to all participants, without whom this work would not have been possible.

\section{Funding}

This work was supported by Aarhus University Hospital, Skej by Research Foundation; Fijoloca Foundation but they had no role in the study. They had no access to data and the authors had the sole responsibility for decisions for the publication.

\section{Conflict of interest}

All authors declare that we have no conflict of interest and conformed to the Helsinki Declaration concerning human rights and informed consent, and that I followed correct procedures concerning treatment of humans and animals in research.

\section{References}

1. Obel N, Engsig FN, Rasmussen LD, Larsen MV, Omland LH, et al. (2009) Cohort profile: The Danish HIV Cohort Study. Int J Epidemiol 38: 1202-1206.

2. Lohse N, Hansen AB, Pedersen G, Kronborg G, Gerstoft J, et al. (2007) Survival of persons with and without HIV infection in Denmark, 1995-2005. Ann Intern Med 146: 87-89.

3. Palella Jr FJ, Deloria-Knoll M, Chmiel JS, Moorman AC, Wood KC, et al. (2003) Survival benefit of initiating antiretroviral therapy in HIV-infected persons in different CD4+ cell strata. Ann Intern Med 138: 620-626.

4. Mannheimer S, Friedland G, Matts J, Child C, Chesney M (2002) The consistency of adherence to antiretroviral therapy predicts biologic outcomes for human immunodeficiency virus-infected persons in clinical trials. Clin Infect Dis 34: 1115-1121.

5. Liu H, Miller LG, Hays RD, Golin CE, Wu T, et al. (2006) Repeated measures longitudinal analyses of HIV virologic response as a function of percent adherence, dose timing, genotypic sensitivity, and other factors. J Acquir Immune Defic Syndr 41: 315-322.
6. Parruti G, Manzoli L, Toro PM, D'Amico G, Rotolo S, et al. (2006) Longterm adherence to first-line highly active antiretroviral therapy in a hospitalbased cohort: predictors and impact on virologic response and relapse. AIDS Patient Care STDS 20: 48-56.

7. Herek, GM, Capitanio JP, Widaman KF (2002) HIV-related stigma and knowledge in the United States: prevalence and trends, 1991-1999. Am J Publ Health 92: 371-377.

8. Ciccarone DH, Kanouse DE, Collins RL, Miu A, Chen JL, et al. (2003) Sex without disclosure of positive HIV serostatus in a US probability sample of persons receiving medical care for HIV infection. Am J Publ Health 93: 949954.

9. Crepaz N, Marks G (2003) Serostatus disclosure, sexual communication and safer sex in HIV-positive men. AIDS Care 15: 379-387.

10. Kalichman SC, DiMarco M, Austin J, Luke W, DiFonzo K (2003) Stress, socia support, and HIV-status disclosure to family and friends among HIV-positive men and women. J Behav Med 26: 315-332.

11. Leserman J (2008) Role of depression, stress, and trauma in HIV disease progression. Psychosom Med 70: 539-545.

12. Bing EG, Burnam MA, Longshore D, Fleishman JA, Sherbourne CD, et al. (2001) Psychiatric disorders and drug use among human immunodeficiency virus-infected adults in the United States. Arch Gen Psychiatry 58: 721-728.

13. Ciesla JA, Roberts JE (2001) Meta-analysis of the relationship between HIV infection and risk for depressive disorders. Am J Psychiatry 158: 725-730.

14. Bravo P, Edwards A, Rollnick S, Elwyn G (2010) Tough decisions faced by people living with HIV: a literature review of psychosocial problems. AIDS Rev 12: 76-88

15. Bouhnik AD, Préau M, Vincent E, Carrieri MP, Gallais H, et al. (2005) Depression and clinical progression in HIV-infected drug users treated with highly active antiretroviral therapy. Antivir Ther 10: 53-61.

16. Ironson G, O'Cleirigh C, Fletcher MA, Laurenceau JP, Balbin E, et al. (2005) Psychosocial factors predict CD4 and viral load change in men and women with human immunodeficiency virus in the era of highly active antiretroviral treatment. Psychosom Med 67: 1013-1021.

17. Clifford DB (2008) HIV-associated neurocognitive disease continues in the antiretroviral era. Top HIV Med 16: 94-98.

18. Hult B, Chana G, Masliah E, Everall I (2008) Neurobiology of HIV. Int Rev Psychiatr 20: 3-13.

19. Vance DE, Farr KF, Struzick T (2008) Assessing the clinical value of cognitive appraisal in adults aging with HIV. J Gerontol Nurs 34: 36-41.

20. Langford SE, Ananworanich J, Cooper DA (2007) Predictors of disease progression in HIV infection: a review. AIDS Res Ther 14: 4-11.

21. Pence BW, Miller WC, Gaynes BN, Eron JJ Jr (2007) Psychiatric illness and virologic response in patients initiating highly active antiretroviraltherapy. Acquir Immune Defic Syndr 44: 159-166.

22. Lima VD, Geller J, Bangsberg DR, Patterson TL, Daniel M, et al. (2007) The effect of adherence on the association between depressive symptoms and mortality among HIV-infected individuals first initiating HAART. AIDS 21: $1175-1183$.

23. Rodkjaer L, Laursen T, Balle N, Sodemann M (2010) Depression in patients with HIV is under-diagnosed: a cross-sectional study in Denmark. HIV Med 11: $46-53$

24. Rodkjaer L, Laursen T, Christensen NB, Lomborg K, Ostergaard L, et al (2011) Changes in depression in a cohort of Danish HIV-positive individuals: time for routine screening. Sex Health 8: 214-221.

25. Rodkjaer L, Sodemann M, Ostergaard L, Lomborg K (2011) Disclosure Decisions: HIV-positive persons coping with disease-related stressors. Qual Health Res 21: 1249-1259.

26. Millard T, Elliott J, Girdler S (2013) Self-management education programs for 
people living with HIVIAIDS: a systematic review. AIDS Patient Care STDS 27: 103-113

27. Scott-Sheldon LA, Kalichman SC, Carey MP, Fielder RL (2008) Stress management interventions for Hiv-positive adults: a metaanalysis of randomized controlled trials, 1989 to 2006. Health Psychol 27: 129-139.

28. Galvan FH, Davis EM, Banks D, Bing EG (2008) HIV stigma and social support among African Americans. AIDS Patient Care and STDs 22: 423 436.

29. Moskowitz JT (2003) Positive affect predicts lower risk of AIDS mortality. Psychosom Med 65: 620-626.

30. Carrico AW, Ironson G, Antoni MH, Lechner SC, Duran RE, et al. (2006) A path model of the effects of spirituality on depressive symptoms and 24-h urinary-free cortisol in HIV-positive persons. J Psychosom Res 61: 51-58.

31. Ickovics JR, Milan S, Boland R, Schoenbaum E, Schuman P, et al. (2006) Psychological resources protect health: 5-year survival and immune function among HIV-infected women from four US cities. AIDS 20: 1851-1860.

32. Gonzalez JS, Penedo FJ, Antoni MH, Durán RE, McPherson-Baker S, et al (2004) Social support, positive states of mind, and HIV treatment adherence in men and women living with HIVIAIDS. Health Psychol 23: 413-418.

33. Moskowitz JT, Folkman S, Acree M (2003) Do positive psychological states shed light on recovery from bereavement? Findings from a 3-year longitudinal study. Death Stud 27: 471-500.

34. Ironson G, Hayward H (2008) Do positive psychosocial factors predict disease progression in HIV? A review of the evidence. Psychosom Med 70: 546-554.

35. Plaeger SF, Collins BS, Musib R, Deeks SG, Read S, et al. (2012) Immune activation in the pathogenesis of treated chronic HIV disease: a workshop summary. AIDS Res Hum Retroviruses 28: 469-477.

36. de Ridder D, Geenen R, Kuijer R, van Middendorp H (2008) Psychological adjustment to chronic disease. Lancet 372: 246-255.

37. Bandura A (1997) Self-efficacy: The exercise of control. New York: W. H. Freeman.

38. Bandura A (1977) Self-efficacy: Toward a unifying theory of behavior change Psychol Rev 84: 191-215.

39. Bandura A (1982) Self-efficacy mechanism in human agency. Am Psychol 37: $122-147$

40. Benight C, Bandura A (2004) Social cognitive theory of posttraumatic recovery: The role of perceived self-efficacy. Behav Res Ther 42: 1129-1148.

41. Chesney MA, Chambers DB, Taylor JM, Johnson LM, Folkman S (2003) Coping effectiveness training for men living with HIV: results from a randomized clinical trial testing a group-based intervention. Psychosom Med 65: 1038-1046.

42. Scott-Sheldon LA, Kalichman SC, Carey MP, Fielder RL (2008) Stress management interventions for HIV-positive adults: a metaanalysis of randomized controlled trials, 1989 to 2006. Health Psychol 27: 129-139.

43. Galvan FH, Davis EM, Banks D, Bing EG (2008) HIV stigma and socia support among African Americans. AIDS Patient Care and STDs 22: 423436.

44. Hawk of the Yellow Wind (2001) The Circle of Life. Lindhardt \& Ringhof Denmak.

45. Ware JE Jr, Sherbourne CD (1992) The MOS 36-item short-form health survey (SF-36). I. Conceptual framework and item selection. Med Care 30: 473-483.
46. Antonovsky A (1987) Unraveling the Mystery of Health - How People Manage Stress and Stay Well, San Francisco: Jossey-Bass Publishers.

47. Chesney MA, Neilands TB, Chambers DB, Taylor JM, Folkman S (2006) A validity and reliability study of the coping self-efficacy scale. $\mathrm{Br} \mathrm{J}$ Health Psychol 11: 421-437.

48. Beck AT, Ward CH, Mendelson M, Mock J, Erbaugh J (1961) An inventory for measuring depression. Arch Gen Psychiatry 4: 561-571.

49. Ritchie, Jane, Liz Spencer and William O'Connor. 2003. "Carrying out qualitative analysis." In Qualitative research practice: A guide for social science students and researchers, edited by Jane Ritchie and Jane Lewis, 219-262. London: Sage.

50. Stata Corp LP, College Station, TX, USA.

51. Eriksson M, Lindstrom B (2006) Antonovsky's sense of coherence scale and the relation with health: a systematic review. J Epidemiol Community Health 60: 376-381.

52. Carstens JA, Spangenberg J (1997) Major depression: a breakdown in sense of coherence? Psychol Rep 80: 1211-1220.

53. Griffiths Ca (2009) Sense of coherence and mental health rehabilitation. Clin Rehab 23: 72-78.

54. Idler EL, Benyamini Y (1997) Self-Rated Health and Mortality: A Review of Twenty-Seven Community Studies. J Health Soc Behav 38: 21-37.

55. Chida Y, Vedhara K (2009) Adverse psychosocial factors predict poorer prognosis in HIV disease: a meta-analytic review of prospective investigations. Brain Behaviour and Immunity 23: 434-445.

56. Gonzalez A, Solomon SE, Zvolensky MJ, Miller CT (2009) The interaction of mindful-based attentionand awareness and disengagement coping with HIVIAIDS-related stigma in regard to concurrentanxiety and depressive symptoms among adults with HIVIAIDS. J Health Psychol 14: 403-413.

57. Gore-Felton C, Koopman C, Spiegel D, Vosvick M, Brondino M, et al. (2006) Effects of quality of life and coping on depression among adults living with HIVIAIDS. J Health Psychol 11: 711-729.

58. Hansen NB, Ghebremichael M, Tarakeshwar N, Zhang H, Kochman A, et al. (2006) Longitudinal effects of coping on outcome in a randomized controlled trial of a coping group intervention for HIV-positive adults with AIDS-related bereavement. Death Stud 30: 609-636.

59. Smith NG, Tarakeshwar N, Hansen NB, Kochman A, Sikkema KJ (2009) Coping mediates outcome following a randomized group intervention for HIVpositive bereaved individuals. J Clin Psychol 65: 319-335

60. Rodkjaer L, Chesney MA, Lomborg K, Ostergaard L ,Laursen T, et al. (2014) HIV-infected individuals with high coping self-efficacy are less likely to report depressive symptoms: A cross-sectional study from Denmark. International Journal of Infectious Diseases. Int J Infect Dis 22: 67-72.

61. Campbell M, Fitzpatrick R, Haines A, Kinmonth AL, Sandercock $P$, et al. (2000) Framework for design and evaluation of complex interventions to improve health. BMJ 321: 694-696.

62. Craig P, Dieppe P, Macintyre S, Michie S, Nazareth I, et al. (2008) Developing and evaluating complex interventions: the new Medical Research Council guidance. BMJ 337: a1655

63. Carrico AW, Antoni MH (2008) Effects of psychological interventions on neuroendocrine hormone regulation and immune status in HIV-positive persons: a review of randomized controlled trials. Psychosom Med 70: 575584.

Copyright: (c) 2014 Rodkjaer L, et al. This is an open-access article distributed under the terms of the Creative Commons Attribution License, which permits unrestricted use, distribution, and reproduction in any medium, provided the original author and source are credited. 